\title{
Educação Ambiental e os termos meio ambiente e impacto ambiental na visão de alunos do ensino superior da região da grande Florianópolis - SC
}

\author{
Paola May Rebollar \\ PPG em Agroecossistemas, Centro de Ciências Agrárias \\ Universidade Federal de Santa Catarina \\ Servidão Ipanema, 127 \\ CEP 88058-470, Florianópolis - SC, Brasil \\ lagunapaola@yahoo.com.br
}

Submetido em 18/10/2008

Aceito em 02/03/2009

\section{Resumo}

As preocupações ambientais no Brasil no século XX se intensificaram com a percepção dos impactos que as atividades humanas geram à biodiversidade. Para que seja possível desenvolver ações visando evitar impactos toda a sociedade deve compreender a problemática ambiental. Projetos de educação ambiental auxiliam neste esclarecimento. Quando implantados em cursos superiores apresentam grande potencial, já que os estudantes podem multiplicar conhecimentos ambientais em seus locais de trabalho. Diante disso, esta pesquisa buscou: a) registrar as práticas ambientais vivenciadas por alunos durante sua formação profissional e b) investigar a visão destes alunos sobre os termos meio ambiente e impacto ambiental. Foram empregadas entrevistas semiestruturadas com 102 alunos de duas universidades da região da Grande Florianópolis. A análise dos dados considerou a freqüência das respostas obtidas. Os resultados apontaram para a inexistência de programas estruturados de educação ambiental apesar de existirem atividades relacionadas à questão ambiental. Os conceitos elaborados pelos alunos apresentaram predominância da perspectiva antropocêntrica, onde a natureza é vista como fornecedora de bens. Este levantamento apontou que os programas de educação ambiental oferecidos a alunos de ensino superior precisam de reflexões teóricas que permitam distinguir com clareza as perspectivas sobre as quais são construídos os conceitos relacionados a problemática ambiental.

Unitermos: educação ambiental, meio ambiente, impacto ambiental

\section{Abstract}

Environmental education, the environment and impact assessment in the view of college students in Florianópolis/SC. Environmental concerns increased in Brazil in the $20^{\text {th }}$ century with the perception of the impacts that human activities have on biodiversity. Society needs to understand such environmental concerns in order to develop actions that prevent these impacts. Projects on environmental education can help in this understanding. When these projects are implemented in college they show a high potential since students can multiply their environmental knowledge in their places of work. Thus, this research was focused on (a) registering the environmental practices offered to students during their time in college and (b) investigating the students' perspectives about the environment and environmental impact. Semi-structured interviews were used with 102 students at two universities in the greater Florianópolis region. The data analysis considered answer frequency. 
The results indicated the existence of many kinds of environmental activities in these universities, but these activities are not organized in structured programs. The answers pointed to the predominance of an anthropocentric perspective, where nature is seen as material provider. The research concluded that environmental programs offered to college students need theoretical reflections to distinguish with clarity the different perspectives over which concepts related to the environmental concerns are built.

Key words: environmental education, environment, impact assessment

\section{Introdução}

Intelectuais de diversos países europeus e americanos apresentaram preocupações com questões ambientais desde o século XVIII. No Brasil, José Bonifácio foi um dos primeiros a escrever sobre o tema (Pádua, 2002).

No século XX, os efeitos ambientais provocados por diversas ações humanas passaram a ser cada vez mais significativos. As atividades industriais, energéticas e agrícolas nos hemisférios norte e sul modificaram fortemente os ambientes naturais e a biodiversidade necessária para sua continuidade. Diante da necessidade de manter o ambiente natural, tem início o debate entre conservacionismo (proteção da natureza prevendo sua utilização racional pelas sociedades humanas) e preservacionismo (proteção da natureza independente dos interesses humanos) (Diegues, 1997; Neder, 2002).

Além destas discussões, surge também intensa discussão sobre a compatibilidade dos modelos de desenvolvimento em curso e a preservação ambiental (Sánchez, 2006). Segundo este autor, essa discussão se estende por 3 aspectos principais: a) ecológico, visando gerar o menor impacto possível, b) econômico, já que é mais barato prevenir do que corrigir e c) ético, porque a preservação e conservação são necessidades para manutenção da qualidade da vida humana.

A expressão meio ambiente se populariza neste debate. O significado desta expressão oscila entre dois pólos (Godard, 1992; Bernardes e Ferreira, 2003). De um lado, está a visão da natureza como fonte de bens, "meio de onde a sociedade extrai os recursos essenciais a sobrevivência e os recursos demandados pelo processo de desenvolvimentos sócio-econômico" (Sánchez, 2006, p. 21). De outro lado está a percepção de que a natureza, além de fornecer bens, também desempenha funções de suporte para a continuação das formas de desenvolvimento material e social (Sánchez, 2006). No espectro entre um pólo e outro, diversos termos surgiram em várias disciplinas como recursos naturais e recursos humanos, patrimônio natural e cultural, paisagem, capital natural e social.

A partir disto, pesquisadores destacam a construção de pelo menos três maneiras de conceituar meio ambiente. Uma destas maneiras é chamada biocêntrica (Sánchez, 2006), naturalista (Reigota, 1991; Bezerra e Gonçalves, 2007) ou objetiva (Theys, 1993). O meio ambiente é a natureza. Este pode ser explicado como um conjunto de objetos naturais (sociedades humanas, fauna, flora, água, etc.) (Morán, 1990). Estes objetos podem ser percebidos "em diferentes escalas (do pontual ao global) e níveis de organização (do organismo a biosfera), e as relações entre eles (ciclos, fluxos, redes cadeias tróficas)" (Sánchez, 2006, p.22).

Outra forma de conceituar meio ambiente é denominada antropocêntrica (Reigota, 1991; Sánchez, 2006; Bezerra e Gonçalves, 2007) ou subjetiva (Theys, 1993). Aqui, meio ambiente é um sistema de relações entre sujeitos (humanos) e objetos (fauna, flora, água, etc.) e entre sujeitos pela posse ou controle dos objetos, o que gera conflitos. As percepções sobre ambiente são relativas, e sempre fragmentadas, porque são filtradas pelos sistemas sociais, costumes, religiões. Natureza é algo externo aos indivíduos. Os projetos com esta visão são chamados de desenvolvimentistas ou produtivistas (Sánchez, 2006).

O terceiro conceito de ambiente é chamado de globalizante (Reigota, 1991; Carneiro, 1999; Bezerra e Gonçalves, 2007) ou tecnocêntrico (Theys, 1993) Nesta visão, sociedade e natureza interagem pela "relação/ interação, dependência/equilíbrio, inclusão/globalidade e responsabilidade" (Carneiro, 1999). Para tanto a sociedade precisa gerir, ou seja, ordenar e reordenar 
constantemente sua relação com o mundo natural (Sánchez, 2006).

O termo impacto ambiental foi construído nesta discussão. Está baseado na perspectiva globalizante, onde o ambiente é o meio de vida, além de fornecer recursos naturais (Sánchez, 2006). A partir destas reflexões se desenvolve a noção de poluição na década de 1960. Esta noção se refere à matéria depositada no entorno dos seres vivos. No entanto, diversas atividades humanas causam perturbações ambientais que não estão ligadas a emissão de poluentes. Por isso, "o conceito de poluição foi ora sendo substituído, ora complementado pelo conceito mais abrangente de impacto ambiental" (Sánchez, 2006, p.26).

Por outro lado, pesquisadores têm apontado a Educação Ambiental (EA) como uma estratégia para enfrentar a necessidade de compatibilizar desenvolvimento econômico e preservação/conservação de ecossistemas. Para Jacobi (2003): "a reflexão sobre as práticas sociais, em um contexto marcado pela degradação permanente do meio ambiente e do seu ecossistema, cria uma necessária articulação com a produção de sentidos sobre a educação ambiental".

Carvalho (2001) parte da idéia da EA como mediação educativa. Esta autora questiona a idéia de uma única EA e chamando a atenção para diferentes matrizes teórico-pedagógicas que compõem os projetos (Carvalho, 2001). Esta diversidade permite que seja possível adaptar tais projetos a diferentes contextos histórico-culturais. Esta adaptação pode assegurar maior efetividade dos procedimentos em relação aos objetivos da EA.

Sorrentino et al. (2005) apontam que EA apresentase como uma perspectiva crítica e emancipatória que busca iniciar processos individuais e coletivos de mudanças culturais e sociais. Apenas através destas mudanças, os conceitos relacionados a problemática ambiental podem ser internalizados e presentes nas ações cotidianas.

A busca científica pela objetividade fez com que diferentes disciplinas construíssem seu vocabulário próprio, onde as palavras têm significados exatos. No entanto, a EA é fortemente interdisciplinar e precisa agregar pesquisadores de diferentes disciplinas para compreender, avaliar e intervir positivamente no planejamento das ações humanas. Este trabalho foi construído a partir das questões: quais tipos de atividades em Educação Ambiental são oferecidas a alunos de cursos superiores com habilitação para trabalhar nestas questões, e que conceitos sobre o meio ambiente estão sendo construídos a partir destas atividades. Buscando responder estas questões, os objetivos deste trabalho foram: a) registrar as práticas ambientais vivenciadas por estes alunos durante sua formação profissional e b) investigar a visão de alunos do ensino superior sobre os termos meio ambiente e impacto ambiental.

\section{Material e Métodos}

A região da grande Florianópolis está localizada na região central do litoral catarinense. Possui clima subtropical úmido. Originalmente era recoberta pela floresta ombrófila densa, mas atualmente se encontra apenas vegetação secundária com poucas palmeiras e agriculturas cíclicas (Klein, 1978). A zona rural é composta de propriedades entre 2 e $50 \mathrm{ha}$, onde a maior parte dos produtores são proprietários. Arroz, batata, feijão, alho, fumo, banana, mandioca, aves são os principais produtos locais. A maior parte da população vive na zona urbana. É composta por 21 municípios (Águas Mornas, Alfredo Wagner, Angelina, Anitápolis, Antônio Carlos, Biguaçu, Canelinha, Florianópolis, Garopaba, Governador Celso Ramos, Leoberto Leal, Major Gercino, Nova Trento, Palhoça, Paulo Lopes, Rancho Queimado, Santo Amaro da Imperatriz, São Bonifácio, São João Batista, São José, São Pedro de Alcântara, Tijucas). As principais atividades industriais da região se referem a construção civil, têxteis, plásticos, pesqueira. Concentra diversas atividades de serviços como turismo, consultorias e universidades (EPAGRI, 1999). No que se refere ao ensino superior, existem 6 universidades na região e mais de 50 cursos.

A pesquisa foi realizada nos meses de julho, agosto e setembro de 2008. Foram entrevistados 102 alunos de duas universidades da região da grande Florianópolis em Santa Catarina. Estes alunos freqüentam os cursos de Engenharia de Agronomia, Engenharia Ambiental e 
Zootecnia e estão na $2^{\mathrm{a}}, 4^{\mathrm{a}}, 6^{\mathrm{a}}, 8^{\mathrm{a}}$ e $9^{\mathrm{a}}$ fases. A técnica utilizada foi a entrevista semi-estruturada (Bernard, 1988; Alexiades, 1996). Esta técnica dá maior liberdade de expressão ao informante que não se restringe a responder apenas questões rígidas e fechadas. Nestas entrevistas foi solicitado que os alunos escrevessem sobre três pontos específicos: 1) quais atividades em educação ambiental freqüentaram durante a formação profissional?; 2) defina o que é meio ambiente, e 3) defina o que é impacto ambiental.

As atividades vivenciadas pelos alunos foram descritas e apresentadas em tabelas. No que se refere aos conceitos de meio ambiente e impacto ambiental a análise dos dados considerou a freqüência das respostas obtidas. Estas freqüências foram relacionadas com as classificações usadas na literatura científica.

\section{Resultados}

A faixa etária dos alunos entrevistados oscilou entre 19 e 36 anos. Dos colaboradores 34 cursavam Agronomia, 36 eram alunos de Zootecnia e 32 eram alunos de Engenharia Ambiental.

Dos 102 alunos participantes, 61 são originários de Santa Catarina (28 da região da grande Florianópolis, 20 da região oeste, 9 do sul do estado e 4 do norte catarinense), 25 são originários do Rio Grande do Sul, 4 são do estado do Paraná, 9 são de São Paulo e 3 são da região nordeste do Brasil. Estas informações estão sintetizadas na Tabela 1.

Os alunos destacaram atividades como palestras sobre hábitos de consumo e legislação ambiental e agrária, participação em programas de monitoramento de padrões de qualidade de água, participação em programas de processamento de resíduos sólidos e líquidos entre as atividades em educação ambiental freqüentadas no período de formação acadêmica. Todos os alunos entrevistados informaram já ter participado de palestras ou seminários, e de saídas de campo para conhecer e estudar locais de ecossistemas conservados ou em regeneração, para aterros sanitários ou unidades produtivas diversas.

TABELA 1: Local de origem dos alunos entrevistados.

\begin{tabular}{|l|c|c|}
\hline \multicolumn{1}{|c|}{ Local de origem } & Total de alunos & Porcentagem \\
\hline Santa Catarina & $\mathbf{6 1}$ & $\mathbf{5 9 , 8 \%}$ \\
\hline $\begin{array}{l}\text { Região da grande } \\
\text { Florianópolis }\end{array}$ & 28 & $27,4 \%$ \\
\hline Região Oeste & 20 & $19,6 \%$ \\
\hline Região Sul & 9 & $8,8 \%$ \\
\hline Região Norte & 4 & $3,9 \%$ \\
\hline Rio Grande do Sul & $\mathbf{2 5}$ & $\mathbf{2 4 , 5 \%}$ \\
\hline Paraná & $\mathbf{4}$ & $\mathbf{3 , 9 \%}$ \\
\hline São Paulo & $\mathbf{9}$ & $\mathbf{8 , 8 \%}$ \\
\hline Nordeste & $\mathbf{3}$ & $\mathbf{2 , 9 \%}$ \\
\hline
\end{tabular}

${ }^{1}$ Este item é o somatório da região da grande Florianópolis, região oeste, região sul e região norte.

Dos 34 alunos participantes que cursavam Agronomia, 17 fizeram algum estágio voluntário ou remunerado relacionado a questões ambientais e 23 já participaram de algum evento do tipo congresso ou simpósio cujo tema estava relacionado às questões ambientais. Os alunos do curso de Zootecnia também já participaram estágios voluntários ou remunerados (11 indivíduos) e de eventos (24 indivíduos). Já no curso de Engenharia Ambiental 20 alunos já foram estagiários e 27 participaram de eventos (Tabela 2).

TABELA 2: Atividades em educação ambiental vivenciadas pelos alunos entrevistados.

\begin{tabular}{|l|c|c|c|c|c|}
\hline \multicolumn{1}{|c|}{ Atividades } & Total de alunos & Agronomia & Zootecnia & $\begin{array}{c}\text { Engenharia } \\
\text { Ambiental }\end{array}$ & \begin{tabular}{c} 
\% da amostra \\
\hline Palestras e Seminários
\end{tabular} \\
\hline Estágios & 402 & 34 & 36 & 32 & $100 \%$ \\
\hline Participação em eventos & 74 & 17 & 11 & 20 & $47,1 \%$ \\
\hline Saídas de campo & 102 & 34 & 36 & 27 & $72,5 \%$ \\
\hline
\end{tabular}


No que se refere aos conceitos de meio ambiente, 23 alunos definiram a expressão a partir de perspectivas biocêntricas. O principal indicador desta perspectiva foi o enquadramento das sociedades humanas no mesmo patamar de importância dos demais elementos ambientais:

- "Conjunto de fatores que englobam aspectos físicos, biológicos e antropológicos."

- "Local que pode designar certa atividade como meio rural, meio urbano ou locais preservados."

- "Conjunto de características e interações físicas, químicas, biológicas e humanas."

Outros 64 participantes apontaram definições baseadas na visão antropocêntrica. Para identificar esta visão foi utilizado como indicador a externalização do ambiente natural.

- "Lugar onde se vive, com suas características e condicionamentos geofísicos."

- "Local a ser estudado, englobando um todo como solo, água, fauna, flora, espaço no qual a natureza está interagindo."

- "Local onde se disponibiliza matérias-primas."

- "Local onde se realizam atividades."

- "Algo relacionado com a natureza."

- "Local onde se encontra o ecossistema."

- "Espaço físico relacionado com a fauna e a flora."

- "Local que o homem pode modificar."

Dos alunos entrevistados, 13 definiram meio ambiente com base em visões globalizantes (Tabela 3). A presença das noções de equilíbrio e dependência entre sociedade e natureza ou gestão dos recursos naturais para manutenção da vida humana foram os principais indicadores desta visão sobre o meio ambiente.

- "É a interação entre sociedade e natureza visando equilíbrio."

- "Conjunto de componentes humanos, vegetais, animais, solos, águas que têm entre si uma relação de dependência."

- "Conjuntos de aspectos necessários para garantir a vida no planeta (humana, animal, vegetal, etc.)"
TABELA 3: Conceitos de meio ambiente expressados pelos alunos entrevistados.

\begin{tabular}{|l|c|c|}
\hline \multicolumn{1}{|c|}{ Conceitos } & Total de alunos & $\mathbf{\%}$ \\
\hline Biocêntricos & 23 & $23,4 \%$ \\
\hline Antropocêntricos & 64 & $63,3 \%$ \\
\hline Globalizantes & 13 & $13,3 \%$ \\
\hline
\end{tabular}

O último aspecto das entrevistas buscava perceber os conceitos de impacto ambiental dos alunos entrevistados. De um lado, surgiram definições reducionistas (57 alunos). Estas definições foram classificadas a partir da ênfase apenas nos impactos negativos e na introdução de elementos externos (poluição) como fator impactante.

- "Condição de efetuar mudança no aspecto de origem de um determinado meio ou ser, comprometendo sua estabilidade por algum fator adverso."

- "Possíveis danos causados ou anomalias, diferenças no meio comum, um impacto pode ser gerado por nós seres humanos a um meio ou as próprias influências naturais impactando o mesmo."

- "Perturbação, variação ou modificação ocorrida em uma região (macro e micro), em conseqüência de fatores externos introduzidos em um sistema."

De outro lado, foram observados conceitos mais amplos (45 colaboradores). Estes tipos foram reconhecidos pelo destaque para a possibilidade de impactos negativos e positivos, sempre associados às ações humanas (Tabela 4).

- É qualquer evento que altere a rotina, seja de forma benéfica ou maléfica.

- Alteração significante, ruim ou benéfica, nas características de um meio ambiente, provocadas pelas ações humanas.

- Situação em que o meio sofre uma alteração atípica que pode ser boa ou ruim para os elementos envolvidos.

TABELA 4: Conceitos de impacto ambiental expressados pelos alunos entrevistados.

\begin{tabular}{|l|c|c|}
\hline \multicolumn{1}{|c|}{ Conceitos } & Total de alunos & \% \\
\hline Reducionistas & 57 & $55,8 \%$ \\
\hline Amplos & 45 & $44,1 \%$ \\
\hline
\end{tabular}




\section{Discussão}

Com relação a expressão meio ambiente foi observado o predomínio da visão antropocêntrica entre os alunos. Este fato aponta para sua predominância também entre os educadores que repassam informações ambientais. Esta visão traz como desvantagem o afastamento entre sociedades humanas e meio natural. Esse afastamento leva a um sentimento de independência entre esses dois aspectos, que é irreal. A partir deste sentimento de independência é possível elaborar construções mentais que justificam a exploração irracional dos recursos e a degradação ambiental inconseqüente, que podem chegar ao ponto de inviabilizar o modo de vida humano.

Bezerra e Gonçalves (2007) buscaram identificar os conceitos de ambiente construídos por um grupo de professores de uma escola agrotécnica em Pernambuco e encontraram resultados diferentes. Estes resultados apontavam para o predomínio da visão biocêntrica, destacando meio ambiente como um espaço físico. Esta visão também estava presente nas respostas dos alunos entrevistados, porém em menor proporção. É interessante observar que os estudantes que participaram desta pesquisa cujos conceitos são biocêntricos, também identificaram o meio ambiente com um espaço físico.

A visão globalizante foi expressa pela minoria dos alunos, o que aponta para sua pequena representatividade também entre aqueles que disponibilizam informações aos estudantes. Bezerra e Gonçalves (2007) encontraram esta perspectiva em $25 \%$ dos professores entrevistados. É a partir desta concepção que podem ser elaborados planos de gestão dos recursos naturais e políticas públicas de médio e longo prazo visando a sustentabilidade das atividades humanas.

No que se refere aos conceitos sobre a expressão impacto ambiental surgiu um contraponto entre definições reducionistas e outras mais amplas. A evolução da noção de impacto ambiental ocorreu a partir do termo poluição. Este termo foi percebido como muito restrito, já que dava conta apenas dos efeitos produzidos pela deposição de materiais provenientes de atividades humanas no entorno das sociedades. No entanto, diversos outros aspectos causam problemas ambientais como supressão de elementos do ambiente e a inserção de elementos no ambiente. Além disso, nem todas as atividades humanas são maléficas, muitas podem produzir efeitos positivos.

No entanto, muitas vezes a expressão impacto ambiental é utilizada como sinônimo de poluição. Além disso, esta expressão também é utilizada para indicar apenas aspectos negativos. A maior parte dos alunos entrevistados definiu impacto desta forma reducionista. $\mathrm{O}$ mesmo ocorreu com os professores que colaboraram com a pesquisa de Bezerra e Gonçalves (2007). De forma geral, foi possível observar que os alunos que conceituaram impacto de forma ampla estão ou estiveram ligados a projetos de avaliação de impactos ambientais para fins de licenciamento oficial.

A questão proposta aos alunos entrevistados relacionada as atividades em EA freqüentadas durante a graduação levou os alunos a confundirem atividades relacionadas a problemática ambiental com atividades em EA. A maior parte das atividades apontadas pelos alunos como resposta a esta questão não pertencem a projetos estruturados e, portanto, não podem ser consideradas como atividades em educação ambiental. Segundo Bezerra e Gonçalves (2007) existem a tendência para enquadrar erroneamente as atividades práticas de uma disciplina como atividades em educação ambiental. Temas como consumo, legislação, tratamento de resíduos e padrões de qualidade foram relacionados, diretamente, com o termo educação ambiental. No entanto, estas atividades não possuem uma unidade teórica e apresentam características das diferentes correntes de pensamento existentes nas discussões relativas a problemática ambiental.

Apesar disso, estas atividades são importantes fontes de informação sobre as questões ambientais de que dispõem os alunos. Por isso, os conceitos elaborados sobre as expressões meio ambiente e impacto ambiental decorrem, em grande parte, da forma como estas informações são repassadas e absorvidas pelos estudantes. Segundo Reigota (1991), as concepções de ambiente dos envolvidos em projetos educacionais são determinantes dos tipos de projetos a serem desenvolvidos. 
A problemática ambiental infere a necessidade de mudanças nos padrões de comportamento humanos para diminuir o ritmo de degradação dos aspectos necessários a nossa sobrevivência. No entanto, estas mudanças serão efetivas somente quando a sociedade compreender com clareza sua necessidade. A EA pode ser uma ferramenta na mudança de mentalidades e de atitudes na relação homem-ambiente (Bezerra e Gonçalves, 2007). Para Caporal e Costabeber e (2000, p.33), a EA permite "o desenvolvimento de uma prática social mediante a qual os sujeitos do processo buscam a construção e sistematização de conhecimentos que os levem a incidir conscientemente sobre a realidade". Como apontado por Carvalho (2001) a EA é um processo que requer mudanças na sua identidade e na suas posturas diante do mundo.

Bezerra e Gonçalves (2007) identificaram a necessidade de trabalhar questões ambientais com os professores para sensibilizá-los quanto ao pertencimento nas questões ambientais e torná-los multiplicadores dentro da sala de aula. A EA abre espaço para repensar práticas sociais bem como o papel dos professores como mediadores e transmissores de conhecimentos (Jacobi, 2003). Segundo este autor, estes conhecimentos são necessários "para que os alunos adquiram uma base adequada de compreensão essencial do meio ambiente global e local, da interdependência dos problemas e soluções e da importância da responsabilidade de cada um" (Jacobi, 2003, p.204)

Paralelamente, é interessante expandir o universo destes multiplicadores de conhecimentos ambientais para outros profissionais, além dos professores. Isso pode acontecer pela inserção de programas de educação ambiental no período de formação acadêmica. Apesar de, em alguns casos, estes programas não existirem oficialmente, sua necessidade já foi sentida e atividades relacionadas a esta temática são oferecidas aos alunos regularmente. A oficialização destes programas permitiria reflexões críticas sobre seus pressupostos teóricos, o que com certeza somaria para seu aprimoramento constante.

Este trabalho buscou enfatizar que a educação ambiental durante a formação acadêmica pode ser uma estratégia para potencializar as contribuições de profissionais de diferentes áreas no esclarecimento de aspectos ambientais junto às comunidades. Este esclarecimento pode ampliar a capacidade de participação pública destas comunidades. Para que isto ocorra, os programas de educação ambiental oferecidos a alunos de ensino superior precisam de reflexões teóricas que permitam distinguir com clareza as perspectivas sobre as quais são construídos os conceitos relacionados a problemática ambiental. Inserir projetos de EA na formação de profissionais de extensão rural, gestão e planejamento e consultaria ambiental pode ser um bom passo para ampliar o alcance de atividades desenvolvidas na academia.

\section{Referências}

Alexiades, M. N. 1996. Collecting ethnobotanical data: an introduction to basic concepts and techniques. In: Alexiades, M. N. (Org.). Selected guidelines for ethnobotanical research: A field manual. NYBG, New York, USA, p.53-94.

Bernard, H. R. 1988. Research methods in cultural anthropology. Sage Publications, California, USA, 122pp.

Bernardes, J. A.; Ferreira, F. P. M. 2003. Sociedade e natureza. In: Guerra, A. J. T. e Cunha, S. B. (Org.). A questão ambiental sob diferentes abordagens. Bertrand Brasil, Rio de Janeiro, Brasil, p.17-42.

Bezerra, T. M. O.; Gonçalves, A. A. C. 2007. Concepções de meio ambiente e educação ambiental por professores da Escola Agrotécnica Federal de Vitória de Santo Antão - PE. Biotemas, 20 (3): 115-125.

Caporal, F. R.; Costabeber, J. A. 2000. Agroecologia e desenvolvimento rural sustentável: perspectivas para uma nova extensão rural. Agroecologia e Desenvolvimento Rural Sustentável, 1 (1): 16-37.

Carneiro, S. M. C. 1999. A dimensão ambiental da educação escolar de $1^{\mathrm{a}}$ a $4^{\mathrm{a}}$ séries do ensino fundamental na rede pública da cidade de Paranaguá. Tese de Doutorado da Universidade Federal do Paraná, Brasil, 99pp.

Carvalho, I. C. M. 2001. Qual educação ambiental? Elementos para debate sobre educação ambiental e extensão rural. Agroecologia e Desenvolvimento Rural Sustentável, 2 (2): 5-36.

Diegues, A. C. 1997. O Mito do paraíso desabitado nas florestas tropicais brasileiras. In: Castro, E. \& Pinton, F. (Orgs). Faces do trópico húmido: Conceitos e questões sobre desenvolvimento e meio ambiente. Cejup, UFPA/NAEA, Belém, Brasil, 446pp.

EPAGRI, Empresa de Pesquisa Agropecuária e Extensão Rural de Santa Catarina. 1999. Zoneamento agroecológico e sócioeconômico do estado de Santa Catarina. Disponível em $<$ http:// www.epagri.rct-sc.gov.br>. Acesso em 23 de agosto de 2008.

Godard, O. 1992. L'environnement, une polysémie sous-exploitée. In: Jollivet, M. (Org.). Sciences de la nature, sciences de la société: Les passeus de frontières. CNRS Éditions, Paris, França, p.337-344. 
Jacobi, P. 2003. Educação ambiental, cidadania e sustentabilidade. Cadernos de Pesquisa, 118: 189-205.

Klein, R. M. 1978. Mapa fitogeográfico de Santa Catarina. Fundação do Meio Ambiente, Florianópolis, Brasil, 24pp.

Morán, E. F. 1990. A ecologia humana dos povos da Amazônia. Vozes, Petrópolis, Brasil, 367pp.

Neder, R. T. 2002. Crise socioambiental: Estados \& sociedade civil no Brasil (1982 - 1998). Annablume, Fapesp, São Paulo, Brasil, 38pp.

Pádua, J. A. 2002. Um sopro de destruição: Pensamento político e crítica ambiental no Brasil escravagista (17861888). Jorge Zahar Editor, Rio de Janeiro, Brasil, 318pp.
Reigota, M. 1991. O que é educação ambiental. Editora Brasiliense, São Paulo, Brasil, 63pp.

Sánchez, L. E. 2006. Avaliação de impacto ambiental: Conceitos e métodos. Oficina de Textos, São Paulo, Brasil, 495pp.

Sorrentino, M.; Trajber, R.; Mendonça, P.; Ferraro Junior, L. A. 2005. Educação ambiental como política pública. Educação e Pesquisa, 31 (2): 285-299.

Theys, J. 1993. L'environnement à la recherche dúne définition. Notes de méthode de Institut Français de l'Environnement, Paris, França, 46pp. 